\title{
Los mártires olvidados \\ Un estudio de los imaginarios del martirio en la fuente de los dichos
}

\author{
CÉSAR CARBULLANCA NÚÑEZ \\ Universidad Católica del Maule (Chile) \\ cesarcarbullanca@gmail.cl
}

\begin{abstract}
Resumen
El artículo expone diversos paradigmas relativos al martirio en la fuente de los dichos, intentando mostrar que el cristianismo asumió y elaboró tradiciones judías relativas al martirio para indicar que la comunidad vivía los últimos tiempos antes del juicio, explicando el sentido de los hechos que acontecían y específicamente de la muerte de Cristo y los cristianos. De manera particular se detiene en el paradigma de la pasión del justo, el cual postula una inversión escatológica de los sujetos del eschaton que sostiene el carácter bienaventurado de grupos o individuos que son víctimas de la violencia e injusticia. A través de los paradigmas estudiados: el destino violento del profeta y la pasión del justo, los textos muestran una comprensión soteriológica de los sufrimientos y persecución a causa del Hijo del hombre, que funda una nueva perspectiva del martirio.
\end{abstract}

Palabras claves: martirio, rapto, escatología, reino de Dios, apocalíptica.

\section{The martyrs forgotten \\ A study of imaginary martyrdom at the source of these}

\begin{abstract}
The article expose different paradigm about martyrdom at the source saying, trying to show the christianism adopt and elaborate Jews tradition about martyrdom for explain that the community lived the last time before the Juice, explaining the significance of the bistory and specifically de Death of Christ and the Christians. Specifically the article studies the passion of Righteous, who affirm a eschatological inversion of the people of eschaton that support the happiness character of groups that are violence and injustice' victims. Across of paradigms studied: the violence destiny of prophet and passion of Righteous the texts show a soteriological understanding of the suffering and persecution by the son of man, that found a new perspective of martyrdom.
\end{abstract}

Key words: martyrdom, rapture, eschatology, kingdom of God, apocalyptic.

Doctor en Teología, Pontificia Universidad de Comillas (España). Entre sus publicaciones recientes: "Passio Iusti, Passio pauperis en Qumrán. Una discusión sobre el martirio en la teología judía" (2013), e "Il Quarto carme del servo di Dio. Teología del martirio versus teología del sacrificio" (2013).

El artículo es producto del proyecto Fondeyt regular N¹120029. 


\section{E1 martirio en Latinoamérica}

Hablar de martirio en Latinoamérica significa hablar de injusticia y violencia, a esto se debe que comienzo este artículo citando palabras de Pablo de Rohka, pues parece cierto afirmar que ha sido la poesía, más que la teología, quien se ha ocupado de la injusticia y martirio en nuestros países. En el caso de Pablo de Rohka el poema Los arrieros cordilleranos donde el poeta escribe «el Canto en verso indo-latino» aparecen descritos el arriero, el indio, el marino, el minero...:

hambrientos, desarrapados,

Ellos son el pueblo chileno

Y de lo bueno lo bueno,

Grito y médula sumados;

Los mártires olvidados

Y los frutos del país...

lleno de próceres muertos el país se desintegra...

el porvenir trae un eco de osamentas

y el provinciano anda a tientas

entre el vivir y el morir (Nómez, 2013: 162)

El poeta utiliza un término religioso como los mártires olvidados para caracterizar la situación de diversos sujetos del pueblo: minero, arrieros, indios, campesinos, en el contexto de la sociedad capitalista ya instalada; lo interesante es que por un lado, caracteriza el sufrimiento y condición de postración y olvido del minero, del indio, del campesinado como un martirio; no se trata, claro está, ahora, de los mártires cristianos en el coliseo romano sino de un nuevo tipo de martirio que se vive en el territorio nacional. Pero por otro lado, se caracteriza teológicamente el sacrificio del pueblo, de tal manera que éste ya no es anónimo, ya no un número, sino que el poeta logra mostrar el valor histórico de dichos sujetos en la gesta.

Esta última cuestión es la que nos guiará en nuestras reflexiones, ¿es posible llamar a los campesinos, pescadores, obreros de hoy los mártires olvidados? Pudiera parecer una cuestión banal en el contexto de una sociedad secularizada y neoliberal en donde los sujetos y vanguardias de la historia son, no precisamente los pobres y campesinos, sino los grupos económicos, el Banco Mundial u otras entidades que disputas el control del mundo. Pero creemos que no es una un tema circunstancial, pues las consecuencias eclesiológicas que tiene la aceptación de calificar como martirio el sufrimiento y abyección del pueblo, pues es convicción de fe 
que, de la sangre del martirio nace la Iglesia, como lo menciona la Escritura ${ }^{1}$.

\section{1. ¿Qué se entiende por martirio?}

No es novedad que en las últimas décadas, el concepto de martirio registra una ampliación de su significado a partir de la reflexión teológica y literaria en Latinoamérica; así como lo ratifica y menciona el famoso artículo de Karl Rahner un año antes de su muerte, Dimensiones del martirio, con una directa mención del martirio de Monseñor Oscar Arnulfo Romero, en el Salvador. En este artículo el teólogo alemán propone «ciertas ampliaciones del concepto tradicional» (Rahner, 1983: 321) y sostiene que se trata de una existencia que lucha activamente por valores evangélicos. En la historia latinoamericana se puede constatar, ciertamente, una maduración en la convicción teológica acerca del valor soteriológico de los padecimientos del pueblo a causa de la justicia, que nosotros queremos profundizar bíblicamente atendiendo a los paradigmas del martirio en la fuente $\mathrm{Q}$.

Otros autores como G. W. Bowersock (1995), o D. Boyarin (1999), también han tratado el tema. El primero sostiene que martirio no tiene nada que ver con judaísmo, ya que es desarrollado enteramente en un contexto romano; como bien sostiene Boyarin, el presupuesto de esta afirmación radica en que se presupone cristianismo y judaísmo como dos realidades independientes. Por otro lado, Boyarin define el martirio como: «a discurse of dying by God and of talking about it», pero esta definición no nos convence por dos motivos: primero, porque no da cuenta de textos neotestamentarios que hablan acerca del seguimiento de Cristo o de entregar la vida sin tener una estructura lingüística determinada así como lo tendrán los relatos del Martirio de Policarpo o la Exhortatio ad martyrium, tal como lo encontramos en Orígenes. Segundo, porque no da cuenta de los relatos contemporáneos latinoamericanos, como lo ha sostenido J. Sobrino, en donde la causa del morir por, no es in recto, Dios, sino algún valor del reino de Dios, como la justicia o los derechos humanos. Asumimos la perspectiva estudiada por G. Nickelsburg (2006: 278), para quien las formulaciones acerca de la exaltación, resurrección se producen en un contexto de persecución, y en ocasiones de muerte del justo. Este autor no habla de martirio sino de paradigma literario de persecución y exaltación que denomina «Wisdom tale». Para este investigador los relatos

\footnotetext{
1 Jn 19,34: «pero uno de los soldados le abrió el costado con una lanza, y salió al instante sangre y agua»; y Ef 5,25: «Cristo amó a la iglesia y se entregó a sí mismo por ella».
} 
acerca de resurrección, inmortalidad y vida eterna responden a contextos reales, «situaciones históricas concretas». De tal manera que para los creyentes la muerte de los justos representó un «específico problema teológico» (Nickelsburg, 2006: 32).

\subsection{Hipótesis}

Nosotros pensamos que tradiciones judías relativas al martirio han influido en múltiples relatos neotestamentarios, tanto a nivel literario como teológico, dando forma a las distintas formulaciones cristológicas de las comunidades cristianas relativas al sentido de la muerte de Cristo. Por tanto, debemos explicitar nuestra presupuestos acerca del martirio en tiempo bíblicos. Primero, la comprensión cristiana del martirio está vinculada a tradiciones judías, tanto en el caso del destino violento del profeta como en el de la pasión del justo. La comunidad cristiana elaboró estas tradiciones judías aplicándolas a la muerte de Jesús y a la de sus seguidores; segundo, si queremos estudiar el sentido de la muerte de Cristo en el Nuevo Testamento, dependientes de modelos judíos centrados en la entrega de sí, no sólo debemos atender a los textos que hablan expresamente del martirio, si no a otros textos que hablan de la donación de sí mismo, del valor expiatorio, el amor por los amigos, por tanto el estudio que emprendemos en este artículo, tiene un carácter claramente parcial. Tercero, intentando delimitar nuestro campos de investigación, como lo

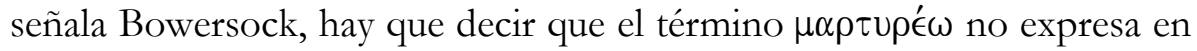
los escritos del Nuevo Testamento el significado que luego encontraremos en textos patrísticos, es decir el derramamiento de la propia sangre por causa de la fe ante el poder político. En el Nuevo Testamento, el

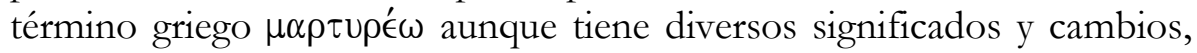
su significado fundamental es de ser testigo o servir de testigo; lo mismo en hebreo $\sigma \gamma(e d)$ у $\varpi \sigma \gamma(e d a h)$, éste es usado como sinónimo de witness, zenge, que pertenece al campo semántico de un proceso judicial (Beutler: 2001, 182-188). Cuarto, consecuentemente con lo ya dicho, el término justo, profeta y mártir tienen una significación teológica semejante, como afirma Lohse (1963: 78) y Baumeister (1980: 6-13.), así no será extraño que cuando hablemos de martirio nos referiremos a los sufrimientos del justo o del profeta. Tanto el profeta, como el justo poseen los rasgos o funciones martiriales como, representatividad, intercesión, exhortación, entrega voluntaria, o sentido expiatorio.

Finalmente, si la exegesis neotestamentaria, monótonamente, señala que la fuente de los dichos sólo tiene el paradigma del martirio perteneciente a la tradición del destino violento del profeta, nosotros expon- 
dremos, en las líneas que siguen, dos paradigmas relativos al martirio en la fuente de los dichos: el destino violento del profeta y la pasión del justo, intentando mostrar que el cristianismo asumió y elaboró tradiciones judías relativas al martirio para explicar el sentido de los hechos que acontecían y específicamente de muerte de Cristo y los cristianos.

\section{Contexto de $\mathbf{Q}$}

En diversas partes del texto de Q aparecen rastros de una situación hostil a la comunidad, ya un análisis terminológico de las bienaventuranzas (Q 6,20-22) ${ }^{2}$ muestra que la situación de la comunidad está caracterizada como «los pobres,... hambre... lloráis,...los hombres os odien, os aparten de sí, os insulten y desechen/persigan vuestro nombre como malo por causa del Hijo del hombre». Se trata por tanto de una comunidad no sólo que experimente el tiempo presente como el arribo del eschaton y que, por consiguiente, vive la pobreza o la angustia del diario vivir como una situación propicia, sino que su situación vital es la de antagonismo y hostilidad, ya del contexto general, como de las autoridades judías. Así lo vemos, por ejemplo, en Mt 10,23: «Cuando os persigan en una ciudad, huid a otra», y en Q 10,10: «Pero en cualquier ciudad donde entréis y no os reciban»; Q 10,16: «El que a vosotros oye, a mí me oye; y el que a vosotros desecha, a mí me desecha; y el que me desecha a mí, desecha al que me envió», y Q 12,8: «Os digo que todo aquel que me

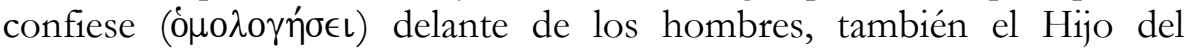
Hombre le confesará delante de los ángeles de Dios». Estas afirmaciones no apuntan solamente a una comunidad que vive el ideal escatológico de la pobreza sino que se trata de una hostilidad que va más allá de una cuestión de palabras como pretende Tuckett (Hofius, 2001: 542-551).

La propuesta hecha por G. Theissen relativa a que la fuente de los dichos tiene como situación vital de vida los «Fringes of society... on the fringes of normal Life» (Theissen, 1992: 40). La comunidad de Q, según este autor, estaría constituida por carismáticos itinerantes «ousiders», sosteniendo que como «ousiders» el primitivo cristianismo itinerante encontró su principal apoyo en gente que vivía al margen de la sociedad: pobres, hambrientos, cobradores de impuestos, prostitutas, personas que pertenecen al más bajo nivel de la sociedad. Theissen ha propuesto como fecha de redacción de Q, el ataque de Calígula en el año 40 d.C. Por su parte, Kloppenborg sostiene una fecha «a finales de los años cincuenta $\mathrm{O}$

2 Utilizamos en general la numeración de los textos de la fuente Q siguiendo el evangelio de Lucas. 
muy al principio de los años sesenta es ciertamente posible» (Kloppenborg, 2005: 121). Todavía más, para Steck, a la luz del dicho de Q 13,3435, sostiene una fecha posterior: «todo parece corroborar la hipótesis de que el dicho sobre Jerusalén es un anuncio del juicio pronunciado entre los años 66 y 70 d.C.» (Steck, 1967: 237-239).

En relación al ambiente de polémica y rechazo que presenta en múltiples pasajes la fuente de los dichos, diversos autores sostienen esta posición (Manson, 1937: 48). Kloppenborg afirma que la fuente esta contextualizada por la polémica contra las autoridades fariseas y legistas, que «muestran un conflicto con fariseos y legistas» (Kloppenborg, 2005: 269). En relación a la figura del Hijo del hombre, y la consideración que la cristología de la fuente de los dichos está inscrita dentro de una imaginarios del martirio es dada por Chr. Tuckett y E. Meadors, el primero, señala que «la afirmación que $Q$ no conoció el sufrimiento de Hijo del hombre necesita algunas modificaciones» (Tuckett, 1996: 253). Lo mismo, Meadors, quien critica a E. Tödt indicando que «su esquema falla tomando en consideración los diversos retratos que aparecen en $\mathrm{Q}$ y en los cuales es de hecho, rechazado por su generación (Q 7,34)» (Meadors, 1997: 134). Existió en Q, la idea que los enviados de Dios son «asesinados y perseguidos» en los últimos días y además que la sangre de los profetas derramada será demandada colmando la medida del pecado... esta secuencia se asemeja a la tradición del martirio presente en texto de Qumrán como 4Q491c, en la cual se presupone el envío de profetas en los últimos tiempos y el destino de sufrimiento antes de su exaltación a los cielos.

\section{El envío del profeta y su destino violento}

\subsection{La historia de Israel como rechazo de los enviados}

Si atendemos a algunos de los dichos de esta fuente, se declara bienaventurados a quienes siguen la huella de los antiguos profetas que han sido perseguidos (ver Lc 6, 12.20; 7,34; 10,13-15; 14,27). En el dicho de Q 6, 23b: «así hacían sus padres a los profetas», pertenece a la tradición del destino violento del profeta. Tuckett explica esto por un recurso a la tesis de O. Steck. A juicio de este último, el v. 51a: «no pertenece originalmente al pedazo de tradición judía», sino tan sólo el versículo 49: «Por esto, la sabiduría de Dios también dijo: 'Les enviaré profetas y apóstoles; y de ellos, a unos matarán y a otros perseguirán'» (Steck, 1967: 22-223).

A juicio de la inmensa mayoría de autores se puede argumentar la existencia de una idea de martirio y rechazo del Hijo del hombre en Q de 
acuerdo a la tradición deuteronomista, es decir, como el envío de profetas al final de los tiempos, así, por ejemplo, en Q 11,46-48:

¡Ay de vosotros, que edificáis los sepulcros de los profetas a quienes mataron vuestros padres! ${ }^{48}$ De modo que sois testigos y confirman los hechos de vuestros padres; a la verdad ellos los mataron, pero vosotros edificáis sus sepulcros.

La falta de un uso técnico del término $\mu \alpha \rho \tau u \rho \in ́ \omega$ se percibe en que este verbo es aplicado en este relato a los adversarios de los profetas y enviados de Dios; los hijos son «testigos y confirman los hechos de los padres», y a continuación sigue en el v. 49:

Les enviaré profetas y apóstoles; y de ellos, a unos matarán y a otros perseguirán; para que de esta generación sea demandada la sangre de todos los profetas que ha sido derramada desde la fundación del mundo (ver Q 7,33$35 ; 13,34)$.

Es interesante analizar la diferencia entre el texto de Jubileos (Jub) 1,12 y Ne 9,26-27, el primero se lee: «enviaré a ellos testigos para exhortarlos, pero no escucharán incluso mataran»; en el segundo dice: «Mataron a tus profetas que testificaban contra ellos para hacerlos volver a ti, y cometieron grandes abominaciones».

Es significativo este texto, pues muestra que la tradición deuteronomista del envío de profetas y su posterior fracaso fue leído comprendiendo que los profetas tienen como misión testificar contra el pueblo; además vemos que en corrientes apocalípticas la identificación de profetas con testigos es ya asumida coincidiendo en la misión de «exhortación contra el pueblo».

A la tradición del destino violento del enviado que cree que el envío del testigo representa los últimos tiempos responden múltiples textos neotestamentarios (Mc 1,2; 9,11; 12,1-11; Lc 6,22-23 par 11,49; Mt 31,32; Hch 7, 52; 1 Tes 2,15-16). En los escritos paulinos como 1Tes 2, 15-16 también encontramos esta tradición, allí se lee: «éstos mataron tanto al Señor Jesús como a los profetas; a nosotros nos han perseguido [...] Así colman siempre la medida de sus pecados». De acuerdo a esta tradición la generación presente 'colma la medida del pecado' que está pronta para el juicio de Dios ${ }^{3}$. También la expresión «ellos los mataron, pero vosotros edificáis sus sepulcros» muestra que se trata de una tradición que

\footnotetext{
3 También es posible que pertenezca a esta perspectiva, la existencia de un misterio de obstinación de Israel que lleva a rechazar a los enviados de Dios. Esto se refleja en el reiterado uso apologético del texto de Is 6,9 en círculos cristianos (Mc 4,11-12).
} 
interpreta la historia de Israel como una actitud de rechazo de los enviados que pasa de padres a hijos. En el dicho de 1Tes 2, 15-16 y en el de Q 11, 49 se cumple la relación de continuidad entre padres e hijos como historia de rechazo de los enviados, pero también la continuidad entre los antiguos profetas y los discípulos de Cristo. En diversos pasajes está un paralelismo entre el destino del Hijo del hombre y el de sus discípulos (Baumeister, 1980: 79). Si la primera continuidad, padres e hijos, establece una relación que lo vincula con esta tradición deuteronomista que muestra una síntesis de la historia de Israel; la fuente Q expresa que esta historia ha sido una historia de rechazo desde Abel hasta Zacarías. En esta tradición judía, el relato de Q 11, 51 // Mt 23, 35 menciona un arco de tiempo que va «desde la sangre de Abel hasta la sangre de Zacarías». La segunda continuidad, profetas y discípulos de Cristo, establece una nueva relación no explicitada en anteriores escritos judíos entre mesianología y martirio.

Es importante notar que la idea presente en el dicho de Q 11,50-51 sobre la sangre de Abel relacionó a éste como un enviado de Dios ${ }^{4}$ : «...sea demandada la sangre de todos los profetas que ha sido derramada desde la fundación del mundo; ${ }^{51}$ desde la sangre de Abel hasta la sangre de Zacarías... la sangre de ellos será demandada de esta generación». Para la tradición judía, Abel es tipo del justo no del profeta, sin embargo, el dicho lo menciona dentro de la serie de profetas enviados por Dios. Lo mismo Zacarías cuya muerte es descrita en 2Cro 24,20, es un sacerdote, no un profeta. La versión de Mt 23,35, presenta «la sangre de los justos» ${ }^{5}$, lo cual encaja mejor con la frase a continuación. Lo fundamental para nuestro objetivo es que ambas figuras son integradas dentro de los enviados de Dios y cuya sangre, según el pensamiento judío, clama por justicia, como afirma Manson (1937: 103), «que tal tipo de sangre (injustamente derramada) clama por venganza es una idea común en el Antiguo Testamento».

4 En el TestAbraham tanto Abel como Enoch son mencionados como «mártires» 12,2 «Abel el proto mártir»; 128v, 8 «Enoch el mártir de verdad».

5 San 4,5 afirma: «...en los procesos de sangre, en cambio, la sangre del reo y la sangre de toda su descendencia penderá sobre el falso testigo hasta el fin del mundo. Porque así lo encontramos en Caín que mató a su hermano, tal como está escrito. Las sangres de tu hermano están gritando. No dice la sangre de tu hermano, sino las sangres de tu hermano, es decir, su sangre y la sangre de su descendencia. Otra explicación: las sangres de tus hermanos, ya que su sangre fue vertida sobre los árboles y sobre las piedras. Por eso fue creado el hombre solo, para enseñarte que todo aquel que destruyere una sola vida en Israel la Escritura se lo computa como si hubiera destruido todo un mundo y todo aquel que deja subsistir a una persona en Israel se lo computa como si dejara subsistir a un mundo entero». 
En esta tradición, tenemos un ejemplo claro de que la cristología asumió textos y tradiciones judías sobre el rechazo de los profetas y testigos enviados por Dios al pueblo; no obstante, en esta tradición no se reflexiona ex profeso sobre la muerte de Cristo, ni su significación soteriológica, a no ser, la de integrar el rechazo y muerte del Hijo del hombre como un caso especial que pone fin a la historia de Israel y lleva a ésta a la ruina y consecuentemente a la acogida de los paganos en el Reino. En este sentido es posible que se entendiese la figura de Jesús como la del profeta escatológico y en este sentido sirvió a una interpretación escatológica de la historia de Israel entendida como rechazo definitivo de los enviados de Dios.

\subsection{Juan el Bautista y el juicio}

En la fuente de los dichos mantiene esta idea del profeta en cuanto en $\mathrm{Q}$ 3,7-8 dice:

¡Generación de víboras! ¿Quién os enseñó a huir de la ira venidera? 8 Producid, pues, fruto digno de arrepentimiento.

Este pasaje muestra al profeta llamando a la conversión y como predicador del juicio venidero. Ambos pasajes son clasificado por Kloppenborg y Strecker como pertenecientes a $\mathrm{Q}^{2}$, responsable de la teología deuteronomista, sin embargo es importante indicar la diferente impronta de Q 7, 18-19 (20) 22-23 donde Juan anuncia a uno que viene «نeres tú el que viene (ó $\epsilon \rho \chi o ́ \mu \epsilon \nu o \varsigma)$ ?»). Se trata de dos perspectivas distintas, la primera es escatológica, sin asociar una figura escatológica a la llegada del juicio; la otra, une la llegada del juicio final a la aparición de un mediador escatológico, según el texto de Mal 3,23 (Hoffmann, 1972, 201). Siguiendo a Kümmel, sostiene Hoffmann que no hay ninguna tradición judía que describa al mesías como «viniendo», no obstante afirma «hier würde eine alte apokalyptische überlieferung von Jesus bzw. Von der Gemeinde aufgenommen». Sin embargo, se puede comprobar que la opinión de Kümmel es errada en diversos textos (Gn 49,10; Nm 24,13; Os 10,12; Ez 21,32; Esr 2,63; Neh 7,65;1 Mac 14,41; Carbullanca, 2011: 63-67). En Q $3,7-9$ se trata sencillamente del juicio que viene, de «la ira que viene» $(\mu \hat{\varepsilon}$

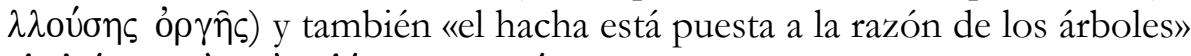

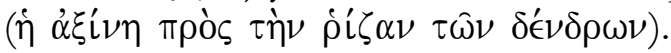

En este dicho, estamos en presencia de una figura del profeta postexílico, el cual se constituye en testigo, en el contexto de un proceso judicial contra el pueblo, y en donde la primera función del profeta, es ser un profeta de conversión del pueblo, y la segunda es la predicación del 
juicio escatológico que viene. El profeta es relacionado con la misión de hacer volver el pueblo a Dios, de advertencia del juicio. En opinión de Kloppenborg el tema del juicio en la fuente de los dichos está relaciona con la historia de Lot, de acuerdo no a la tradición presente en Génesis, sino a la versión que de ésta hace el profeta Ezequiel. En este sentido puede ser apropiado relacionar la figura de Juan el Bautista con la predicación de este profeta. Kloppenborg señala varias similitudes, por ejemplo, sostiene «como Ezequiel, Q amenaza a Jerusalén y su élite con juicio y desolación (13,34-35)» (Kloppenborg, 2005: 161). El profeta, Ezequiel es un centinela (Ez 3,17; Is 52,8), que se le hace responsable por la sangre y conversión del pueblo. En el texto de Ez 3,17, Dios le advierte al profeta que su misión consiste en «amonestar de parte de Dios» una connotación apocalíptica que comenzamos a reconocer a partir de entonces; en estos textos, el profeta es enviado a dar testimonio contra ellos en el día del juicio, cuestión que Kloppenborg (2005: 161) califica de «técnica de avergonzar». Esta misma idea la encontramos en 1 Enoch 12,4. Enoch será señal para dar testimonio contra los hijos de los hombres en el día del juicio ${ }^{6}$. En el periodo bíblico el testigo, al menos en esta tradición, no es quien debe dar la propia vida si no que se trata sencillamente de dar cuenta de lo que se ha visto y oído. Ya con una connotación ética, en textos asociados a los profetas del exilio, el testigo es emparentado con el profeta como atalaya (Ez 3,17; Is 52,8), es decir al profeta se le hace responsable por la sangre y conversión del pueblo. En otro texto de Ez 33,6 dice: «si el centinela ve venir la espada y no toca la trompeta, de modo que el pueblo no es advertido, si viene la espada y se lleva a alguno de ellos, éste es llevado por causa de su pecado, pero yo demandaré su sangre de mano del centinela». Muestra que esta responsabilidad une, el destino del profeta con el del pueblo.

\section{Paradoja y visión deuteronomista}

Además del modelo recién esbozado, hay una serie de textos pertenecientes a la fuente de los dichos que presentan un paradigma del martirio distinto. Estos textos no utilizan el término $\mu \alpha \rho \tau \nu \rho \in ́ \omega$ sino que se caracteriza porque muestran una lógica paradojal ajena al modelo deuteronomista del envío del profeta (Dt 6,20-26; 7,18-23; 10,18-21). En este modelo de martirio describe a personajes que sufren, o son víctimas,

\footnotetext{
6 En el libro de Jubileos señala: «escribió su testimonio y depositó el testimonio sobre la tierra contra todos los hijos de los hombres y sus generaciones» (Jub 4,18.22= 4Q227 fr. 5).
} 
como sujetos elegidos, destinatarios predilectos del eschaton. A este modelo particular lo hemos llamada pasión del justo. A juicio de Nickelsburg (2006: 228), se caracteriza por tener un esquema de humillaciónexaltación. Como es posible demostrar dicho esquema indica una inversión escatológica de valores que se aprecia tanto en textos sapienciales, apocalípticos como en los evangelios (1En 94,3; 1En 25,4; Lc 6,20.22 par Mt 5, 3-11; Lc 10,21.23). Si el modelo deuteronomista era un paradigma de historia nacionalista, el modelo de inversión escatológica conlleva una perspectiva en donde la historia de Israel está inscrita dentro de la historia universal, que ha entrado en una crisis de tal manera que las víctimas, son ahora actores y protagonistas del eschaton. Este segundo paradigma martirial aparece desarrollada mediante utilización de personajes simbólicos como Abel, el Hijo del hombre, o mediante listas de personajes escatológicos: pobres, enfermos como justos.

\subsection{Doctrina de retribución y las bienaventuranzas}

Diversos autores sitúan las bienaventuranzas como pertenecientes al estrato $Q^{1}$, llamado por Kloppenborg (2005: 192-201) «instrucciones exhortatorias». Tanto en la versión de Lucas: Q 6,20 como en el paralelo de Q Mt 5, 2-3 «y él, abriendo su boca, les enseñaba diciendo: 'Bienaventurados los pobres en espíritu, porque de ellos es el reino de los cielos...'», se trata de una lista de sujetos, tradicionalmente considerados malditos, muertos o excluidos de la salvación, ya que según la doctrina clásica, la riqueza, la prosperidad son signos de la bendición de Dios. Pero no sólo la riqueza, sino también la salud corporal y síquica eran considerados signos de la bendición de Dios; estos supuestos teológicos están presentes en el plan del relato del libro de Job, y del cuarto cántico de Isaías. El plan literario del autor de Job, muestra la contradicción del esquema teológico que asocia enfermedad y pobreza a culpa y pecado; por el contrario Job defiende que en su abyección él sigue siendo justo ante Dios; y por tanto la justicia de Dios no está vinculada a la riqueza, y a la prosperidad en este mundo. De un modo similar, el cuarto cántico muestra que el siervo de Dios, paradójicamente, cuando era golpeado, despreciado y asesinado por los suyos, realizaba una función soteriológica por los muchos. Incluso el detalle del último versículo que muestra el cántico acerca de la ignorancia de los reyes, y los muchos acerca de su función soteriológica: «nosotros le tuvimos por azotado, como herido por Dios, y afligido», refleja una comprensión equivocada de los sufrimientos del siervo. Mientras éste cargaba con los dolores, aflicciones y sufrimientos, el grupo «nosotros» creía que Dios lo había herido y hecho sufrir. He aquí la compresión clásica de la doctrina. 


\subsection{Las bienaventuranzas}

Ciertamente, en la fuente de los dichos no existe ninguna referencia al libro de Job o al cuarto cántico de Isaías, pero encontramos el mismo esquema teológico paradojal recogido en las bienaventuranzas que muestran un modelo de pasión del justo, muy distinto al del envío del profeta y su destino violento (Strecker, 2001: 315.). Las cuatro primeras bienaventuranzas exponen esta situación paradojal en que los beneficiarios del eschaton son los pobres, los que sufren y los que lloran (Tucket, 1996: 141). En palabras de J. Jeremías: «...una completa transformación de valores: los pobres llegan a ser ricos, los hambrientos son saciados, los que lloran consolados, los últimos son primeros» (Jeremías, 1971, 248). Los dichos de Q 6,20b-23b, expresan la inminencia del juicio (Russell, 1964: 106; Strecker, 2001: 126-135)según la cual éste viene con transformaciones cósmicas descrito de muy diferentes maneras en los escritos bíblicos, a través de una crisis de proporciones mundiales, que expresa el fin de la historia antes de la emergencia del mundo futuro.

Preliminarmente, nos interesa detenernos en el makarismo de $\mathrm{Q}$ $6,23 \mathrm{c}$ que está dirigido a los discípulos, el cual sería una mezcla de la tradición del destino violento del profeta con aquel de la pasión del justo, en ambos está presente la idea que los discípulos del Hijo del hombre viven los últimos tiempos antes del fin de la historia:

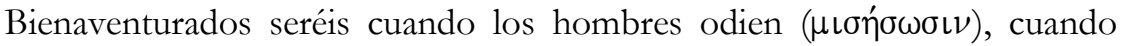

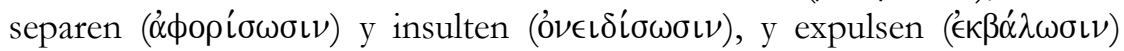
vuestro nombre como si fuera malo, por causa del Hijo del Hombre. ${ }^{23}$ Gozaos en aquel día y saltad de alegría, porque he aquí vuestro galardón es grande en el cielo; pues así hacian sus padres a los profetas.

El makarismo muestra algunas notas importantes. En los vv. 22-23 la persecución muestra una lógica paradójica, que nosotros hemos llamado «inversión escatológica» que acontece mediante la realización del juicio (Jeremías, 1971, 103). Los perseguidos son felices y su causa es ser perseguidos a causa del Hijo del hombre. Por tanto, la bienaventuranza se sostiene en la tensión sobre la inminencia del eschaton según lo expresa el v. 23a: «gozaos en aquel día porque vuestra recompensa será grande en el cielo». El odio, la persecución y el insulto que acontece en el presente a los discípulos es señal de alegría que irrumpe a corto plazo. Por tanto, el esquema presente-futuro está articulado por la idea que realidad negativas son señales de la irrupción y elección del juicio de Dios. Lo mismo lo confirma la primera maldición dedicada a los ricos que sostiene que éstos «ya tienen vuestro consuelo». 
¿Cuáles fueron las razones para que el autor mezclara ambas tradiciones?, ¿tenemos que ver alguna intencionalidad en esta convivencia del modelo deuteronomista de historia con éste que muestra una inversión escatológica? En la línea de hipótesis quizás esto muestra un contexto vital de la comunidad de la fuente de los dichos a juzgar por los dichos de Q 11,30-35 y 13,34.

\subsection{Inversión escatológica}

Hemos señalado ya que la característica fundamental de este imaginario del martirio, es su impronta escatológica que se desarrolla como una lógica paradojal, la cual muestra que la historia ha entrado en una crisis irreversible. En la fuente de los dichos esta impronta escatológica en la cual sujetos sufrientes paradojalmente son elegidos como sujetos activos del reino de Dios.

En este paradigma concurren diversos géneros, pero de modo particular se concentra en el argumento de una superación de la antigua visión de la historia de Israel (Steck, 1967: 256). Si el paradigma del destino violento del mártir enviado todavía se movía en el esquema deuteronomista de la historia nacional, mediante el cual el sufrimiento y muerte es producto del pecado contra Dios; en cambio el modelo de la pasión del justo, el "justo es entregado en manos de los pecadores (paganos)", mediante lo cual Dios salva a las naciones de tal manera que la historia particular entra en crisis debido a esta inversión escatológica (Strecker, 2000: 317). En este modelo la antigua vinculación culpa-sufrimiento es abolida por otra en donde el sufrimiento y muerte de personajes como Abel, José, Jonás, no son a causa de un castigo de Dios a los mismos profetas, sino un instrumento mediante el cual Dios cumple su plan salvífico para todas las naciones.

\subsection{La inversión escatológica y carácter soteriológico de las víctimas}

El modelo de la pasión del justo no es un esquema de asistencialismo divino sino por el contrario es fundamentalmente un modelo soteriológico de pensamiento, el cual constituye como sujetos políticos y éticos a personas o grupos que se les ha privado de dicho estatuto en la sociedad humana, por la violencia fratricida, por su condición heterodoxa, o marginal, por su condición de excluido moral o religioso. Por esto, vemos a partir del post-destierro una doctrina desarrollada por medios del paradigma del justo como lo muestra la historia de José o la del siervo de 
Yahvéh que expresa que es un justo realizando acciones soteriológicas ${ }^{7}$. En textos proféticos encontramos en Is 42, 1: que el siervo «dictará ley a las naciones»; (v.4) «hará justicia», «implantará el derecho»; (v.6) «ser alianza y luz de las gentes»; (v.7) «abrir los ojos ciegos, sacar al calabozo al preso, de la cárcel a los que viven en tinieblas»; Is 49, 6: «levantar las tribus de Israel y de hacer volver a los preservados de Israel»; «poner por luz de las gentes»; Is 50, 4: «para que haga saber al cansado una palabra alentadora».

En la literatura apocalíptica, vemos diferentes personajes no oficiales como Enoch, Abel, el Hijo del hombre son sujetos escatológicos que testigos que realizan funciones soteriológicas, entendida como intercesión, representatividad o expiación (Janowski, 2003, 160) ${ }^{8}$. En esta misma línea Nickelsburg cita a Giorgi para expresar que la exaltación está entendida como juicio del justo sobre los impíos: «el justo juzgará a los impíos» (Nickelsburg, 2006: 82.). Este sentido soteriológico lo encontramos en el dicho de la fuente Q 22,28-30: «vosotros sois los que habéis permanecido conmigo en mis pruebas... y os sentéis sobre tronos para juzgar a las doce tribus de Israel». Es importante atender al paralelo «la disposición del reino» con la de «sentarse en tronos para juzgar a las doce tribus de Israel» (Mc 5,34; 11,52; 12,44; 15,28; Lc7,50).

Más ampliamente en otros textos, la condición de víctima, pareciera tener un carácter ejemplar, es decir, no expía pecados de otros sino soli-

$7 \quad$ También Gn 40,12.18; 41,25-36; 45,3-8: «Dios me ha enviado delante de vosotros para que podáis sobrevivir en la tierra y para salvaros la vida».

8 Se puede comprobar que la figura de Enoch cumple la función de testigo, y realiza la función de sacerdote celeste, hace oraciones, ofrendas, intercede, etc. (Jub 4,25?). En el caso de Abel, la víctima se convierte en Juez, así encontramos TestAbraham 7,13: «...es el hijo del primer hombre creado, aquel que es llamado Abel...se sentó para juzgar a toda la creación y para examinar a justos y pecadores, porque Dios a dicho: no soy yo quien juzgará el mundo, sino cada hombre será juzgado por otro hombre». Existen otros textos, en que la expiación es función una figura escatológica, asi p.e. el profeta del final de los tiempos (11QMelq col II.7; 4Q541; Mal 4,5-6; Mc 1,4). En estos textos la expiación, siendo una función sacerdotal, está desacralizada, al proponer un sacerdocio de ángeles o de un mediador celeste. En 11Melq col. II.7 Melquisedec realiza la liberación anunciada en Is 61,1 en el día del yom quippur «el día de la expiación es el fin del décimo jubileo, en el cual será hecha la expiación para todos los hijos de la luz». En otros textos de un ungido escatológico, asi p.e. en 4Q541 (4QapocrLevib? Ar) (4QTLevid) fragmento 9 col. I: el purificará a todos los hijos de esta generación (v. 2); finalmente, también esta función pareciera ser realizada por la comunidad al tenor del texto de $1 \mathrm{QS}$ col.VIII, 5b-7b donde se atribuye un valor expiatorio a los sufrimientos de la comunidad: en este texto, la expresión "para expiar la tierra» se repite en los vv.3.6b.10b. y en v.3 se trata de una expiación «realizando la justicia», en cambio en vv. 6b y 10b se trata de una «expiación de la nación y decidir el juicio de los impíos». 
cita la justicia para sí mismo, así por ejemplo, la sangre de los justos tienen una función de fiscal ante Dios, por ejemplo, 1Enoch 38,2; 47,1: «se habrá elevado la oración de los justos y la sangre del justo desde la tierra ante el Señor de los espíritus»; tanto la expresión de «la sangre del Justo» como «la oración de los justos» $(47,1)$ remiten al tema de la sangre intercesora del justo9.

\section{Lista de sujetos escatológicos}

\subsection{Inversión escatológica y lista de personajes}

La inversión escatológica utiliza un género literario muy simple, se trata de listas de sujetos que son participes y protagonistas de los bienes del tiempo mesiánico. En la literatura rabínica existe este género en función de especificar a los sujetos excluidos o marginados de participar en el culto, los que son considerados como muertos, o aquellos sospechosos de impureza; también, en la apocalíptica existe el género llamado «listas de cosas reveladas» (Collins, 1984: 17) ${ }^{10}$ vinculado a la idea de la predestinación de los elegidos. Éstas describen los sujetos elegidos del tiempo final, es decir sordos, ciegos, pobres, humildes como testigos del Nuevo Eón que está arribando ${ }^{11}$. En listas pertenecientes al judaísmo rabínico, poseen sobre todo con un carácter casuístico, fundamentalmente excluyente; una lista Tannaita decía «cuatro tipo de hombres son comparados

\footnotetext{
9 Pero además, en algunos textos se sostiene que la condición de persecución, sufrimiento y marginación, es condición para la vida futura, así los que «han muerto en justicia vivirán» (1Enoch 103,4; Sab 1,16-5,23), con una clara relación al Deutero Isaías, se promete la vida futura al justo sufriente. También en 1 Enoch 104,2: «tened esperanza, pues antes habéis sido escarnecidos con maldades y aflicciones, pero ahora brillaréis como las luminarias del cielo»; en TestJudá 25,4, para este texto los que hayan muerto en tristeza, pobreza o necesidad por el Señor recibirán la promesa de la vida: «los que hayan muerto en la tristeza resucitarán en gozo, y los que hayan vivido en pobreza por el Señor se enriquecerán; los necesitados se hartarán; se fortalecerán los débiles y los muertos por el Señor se despertarán para la vida». Esto muestra que la condición de pobre y la desgracia de ser perseguido o asesinado han llegado a ser medio necesario para acceder a su justicia.

10 En el ámbito bíblico encontramos listas en los salmos 82,3-4 y 146,6-10; Is 29,18s; 35,5s; 42,7.18; 61,1-2; y Lc 7,22 par Mt 11,5, estos textos se caracterizan por constituir listas de personajes. En este contexto es importante notar la importancia que adquiere la identificación de determinados personajes en la literatura bíblica «los dos olivos», «los pobres del rebaño» (ver Za 4;11.14; 11,7.9.); «Elías» (Mc 9,11-13); «los buenos pastores» (ver Lc 15,16), etc.

11 La idea que el pueblo es testigo de las acciones de Dios, está presente en el DeuteroIsaias: Isaías $43,10.12 ; 44,8$
} 
con un hombre muerto: el cojo, el ciego, el leproso y la viuda» (Ned 64b Bar); en Qumrán encontramos otra: 4Q266 fr.8 col. I, 6-9 dice: «ningún estúpido o perturbado entrará (en la comunidad) y ningún ingenuo o insano, estos con ojos débiles para ver y el leproso y el cojo o sordo o menor de edad $\rangle^{12}$.

Mediante este género, se subraya uno de los aspectos claves de esta transformación escatológica, a saber, la restauración de justicia de la creación. En ámbitos proféticos, dichas listas sufren un proceso de escatológización, p.e. Is 61,1-2. Ciertamente, desde tiempos pre-exílicos existieron listas: el huérfano, la viuda y el extranjero son sujetos preferenciales de la protección de la Alianza, pero durante el periodo posterior al exílio, esa enumeración se amplía escatológicamente en textos proféticos y apocalípticos como los sujetos, ya no de un código legal, sino los que según el anuncio escatológico son los sujetos privilegiados de la Nueva Alianza. En textos del período post-exílico tales como Is 29, 18-19 vemos una lista:

En aquel tiempo los sordos oirán las palabras del libro y los ojos de los ciegos verán en medio de la oscuridad y de las tinieblas. ${ }^{19}$ Entonces los pobres ( $\pi \tau \omega \chi 0 \grave{i})$ volverán a alegrarse en Yahvéh, y aun los más pobres de los hombres se gozarán en el Santo de Israel.

La liberación del reino, anunciado según el texto de Is 61,1-2, utiliza el género de listas para indicar los destinatarios del eschaton, que los miembros de Qumrán (11QMelq) creyeron acontecería el día de la expiación, el «yom quippur». De acuerdo a esto, en algunos textos, liberación y expiación son contenidos que se superponen. Por tanto, es un error reducir el concepto de expiación al problema del carácter expiatorio de la muerte del mártir. Pareciera que la dirección es la contraria, es decir, el concepto de expiación fue ampliándose cada vez más hasta alcanzar al de la muerte expiatoria. Podemos ver en este texto y en otros semejantes, aparecer «listas de sujetos escatológicos», asi como en 4Q521; 11QMelq (Collins, 1984: 17) ${ }^{13}$ : sordos, ciegos, pobres y

12 Meg II, 4: «Todos son aptos para leer el rollo a excepción de los sordos, idiotas o menores»; RhSh II, 8: «Estos son los no aptos para testimoniar: el que juega a los dados, el usurero, el que hace huir a las palomas, los traficantes con productos del año sabático, y los esclavos»; Yom III, 11; Ker I, 4.5II, 1; Mak III,1.2;San X,1.2.34; 1MQ III,1.2.3; Enoch 69,2-3, 69, 4-12; 4Q269 7:4Q272 1, i-II; 4Q273 4, ii; y en fr. 10 col.I, 7 ;11Q19 col. XIV, 12-18: «ni ciego...ni leproso entrará en mi ciudad del templo», y de CD XV, 15-17: «...y ninguno que sea estúpido o errante debe entrar y ningún débil mental o insano, esos con ojos demasiado débiles para ver, el cojo, o el sordo o un niño de baja edad, ninguno de estos debes permitir entrar en la congregación...».

13 También 1Enoch 41, 1-7; 43,1-2; 60, 11-22; 2 En 23,1; 40, 1-13). 
humildes están en función de mostrar la inversión escatológica: «en ese día los sordos oirán las palabras del libro y los ojos de los ciegos verán en medio de la oscuridad y de las tinieblas...». Esta parte llamada Apocalipsis de Isaias, refleja lo que nosotros hemos llamado una inversión escatológica, la que es el núcleo de esta ideología, en palabras de J. Tabor: «un modelo que tiene como clave una inversión cósmica que es el corazón de la escatología apocalíptica» (Droge \& Tabor, 1992: 70). El esfuerzo de diversos grupos por apropiarse dichos oráculos nos advierte que no estamos frente a textos generales sin ninguna pretensión pragmática, por el contrario el esfuerzo por apropiarse de la terminología de la pobreza por diversos grupos de la sociedad judía nos advierte que dichas listas llegaron a ser en verdad textos programáticos.

En el NT podemos ver dichas listas en textos como Lc 10,21//Mt 11, 25 and Q 7, 22-23// Mt 11, 4-14 donde la lista de sujetos refleja la convicción profética sobre la predestinación de los sujetos del eschaton que se desarrolla en movimientos apocalípticos y se muestra en textos como CD-A col. II, 9.13: «sus nombres fueron establecidos con precisión», y en CD-A, IV , 5: «Aquí está la lista detallada de sus nombres, de acuerdo a su genealogía y la edad de su situación y al número de sus sufrimientos y los años de su residencia y la detallada lista de sus hechos». J. Dupont explicando el texto de Is 61,1-2, señala que «encontramos aquí una lista de beneficiarios del mensaje de salvación que enumera a los pobres, los contritos de corazón, los deportados, los prisioneros, los afligidos y los que tienen el espíritu abatido» (Dupont, 1979: 557). En 1QH 1815 hay un elenco sólo de: los pobres, los de espíritu abatido y los afligidos ${ }^{14}$. También tenemos una lista que enumera a los beneficiarios de la expiación salvífica en Is 29,18-19; y 35,3-6; Jr 31,8-9: las manos débiles, las rodillas vacilantes, el de corazón contrito, ciegos, sordos, cojos y mudos.

\subsection{El tema de la sabiduría}

Una característica particular de los escritos judíos y cristianos radica en la mezcla ininterrumpida de los modelos del martirio. En la fuente de los dichos se muestra la tradición del destino violento de los profetas mezclada con el motivo de la sabiduría (García Martínez, 2003: 1-15) ${ }^{15}$,

\footnotetext{
14 Dupont menciona también a Is 58,6.7.9-11, y Job 24,2-11; 29,12-13.15-17.

15 Múltiples textos en Qumrán hablan de la sabiduría, por ejemplo, 4Q491c (=4Q427, fr.7 col 1+9; 4Q471b); en 1Q27 (1QMyst) se subrayan dos aspectos: en primer lugar, los que no conocen, no comprenden, no sabe y no serán salvados son los impíos. En segundo lugar, las negaciones están en relación al misterio que se revela en la historia pasada, y la era escatológica que está aconteciendo. No se trata de un misterio
} 
así, por ejemplo, en el logion de Q 11, 49-51, comienza con el siguiente encabezado: «Por esto, la sabiduría de Dios también dijo: 'Les enviaré profetas y apóstoles; y de ellos...'». La introducción de la sabiduría hace pensar en un personaje mítico que así como en otros dichos (ver 7,35; $11.31 ; 21,15)$ se presenta como responsable del envío de profetas y testigos al mundo. Sin embargo, es difícil sustraerse a la evidencia intertextual acerca de la relación entre la tradición de la sabiduría en Q y el mito enóquico del descenso y ascenso de la sabiduría en 1 Enoch 42.

En esta misma línea es necesario apuntar al dicho de Q 10, 21, que representa la afirmación cristológica más importante de la fuente de los dichos, pues en ella se va más allá de las «determinaciones de funciones y se indica quién es Jesús» (Gnilka, 1998: 144). Esto sitúa la reflexión en un momento posterior de la reflexión y por tanto es correcto afirmar que la forma de describir el conocimiento recíproco es calificada de «sapiencial». El texto es próximo a Eclo 1,6-9 pero hay otras cinco logia relacionadas con este tema que vincula a Jesús con la Sabiduría. En Q la relación que se establece entre Jesús y la sabiduría consiste en presentarlo como un gran sabio. Se trata de Jesús como un Maestro de Justicia para quien se abren los misterios de Dios, de manera similar a como lo encontramos en Qumrán, aplicados al jefe de la secta. Esta vinculación con la sabiduría se fortalece si consideramos que en la fuente de los dichos se dice que él es mayor que Salomón Q 11,31. Las otras logia se encuentran insertas en la tradición sobre las persecuciones, esto vale para Q 7,35s que considera a Juan el Bautista y a Jesús y a sus seguidores como «hijos de la sabiduría».

\subsection{La revelación de $Q 10,21$}

El dicho de Q 10,21//Mt 11,25-27 pertenece a la tradición de pasión del justo en la cual la revelación es dada a personas que no tienen merecimiento. Esta tradición, que atraviesa tanto al judaísmo como al cristianismo, se aprecia en el uso reiterado de Is 6, 9, que remite al

que acontece en el culto o de espaldas a la historia. La última etapa de la historia, son los últimos días en donde Dios ha ocultado su rostro a su pueblo y el pueblo camina en la oscuridad. Éste periodo es un tiempo de calamidades, en donde prevalece una irracional sabiduría: se viola la Ley, crece la injusticia, se asesina a los santos, etc. (ver 4Esd 15, 52). Para los esenios los escritos bíblicos estaban llenos de misterios, los cuales fueron comunicados a los profetas, y su significado fue mantenido oculto hasta que su interpretación fue revelada al final de los tiempos al Maestro de Justicia. Resulta paradójico que este conocimiento se afirma que Dios revela estos misterios a los pobres, a los hijos de Sadoq (ver 1QH col. XXV, 15); todas las cosas reveladas en los períodos (ver 1QS col. I, 9); todo lo revelado de edad en edad, a los profetas (ver 1QS col. VIII, 15-16). 
principio epistemológico apocalíptico que hemos llamado «principio de ignorancia» y que emerge en diversos relatos como Mc 4,11-12; 13, 32 (ver Jub 1,13) y en la fuente de los dichos en Q Lc 10,21.

...Yo te alabo, Padre, Señor del cielo y de la tierra, porque escondiste estas cosas de los sabios y entendidos y las has revelado a los niños ( $\nu \eta \pi$ íoเs).

Este principio de - esconder a unos y revelar a otros-, es asumido por los relatos neotestamentarios, según el cual, el reconocimiento de los signos de la presencia del reino es una revelación gratuita y selectiva del Padre a los elegidos (niños) y que ha sido ocultado a los sabios y poderosos (Hahn, 1995: 322). El texto pertenece a la fuente de los dichos y muestra que el principio de ignorancia está aplicado no a los principales grupos de la sociedad judía «los sabios y entendidos», sino que a los grupos caracterizados como los «niños». Posiblemente esta expresión designa a los grupos ignorantes de las leyes religiosas. En esta misma línea, los discípulos son considerados, dentro de los ignorantes en materias religiosas como sujetos de revelaciones divinas con lo cual se expresa no sólo un aspecto pasivo de aceptación de la realidad divina sino también como origen eclesial. Los discípulos en la fuente de los dichos no se identifican con los doce sino con un grupo más amplio de los setenta y dos que van de dos en dos, y que en cuanto marginados son origen de un nuevo conocimiento de Dios. La expresión sabios y entendidos está opuesta a niños, simples, y es a juicio de Dupont corriente en el judaísmo para designar a los doctores de la Ley, el rabinato fariseo y sus discípulo. La fuente los llama escribas y legistas, doctores de la ley, entre Jesús y esta élite de Israel, a juicio de Dupont (1979: 85), el «conflicto es continuo».

En el dicho de Q 10,17-24 guarda relación con 10,21:

...Y volviéndose a los discípulos, les dijo aparte: -Bienaventurados los ojos que ven lo que vosotros veis, ${ }^{24}$ pues os digo que muchos profetas y reyes desearon ver lo que vosotros veis, y no lo vieron; y oir lo que ois, y no lo oyeron.

Para Strecker, «el makarismo de los testigos que ven y oyen $\mathrm{Mt}$ 13,16//Lc 10,23) acentúa el carácter escatológico del tiempo de Jesús como cumplimiento de la expectación profética» (Strecker, 2001: 131) está en continuidad con lo que ya hemos desarrollado en relación a la sabiduría y establece una relación con una tradición martirial apocalíptica: «muchos profetas quisieron ver y no vieron, quisieron escuchar y no escucharon...»; así que de acuerdo a este dicho, los discípulos de Cristo son testigos, en su calidad de ignorantes e incultos, del arribo del escha- 
ton, por tanto este dicho de Q 10,17-24 contienen implícitamente el concepto de martirio.

Esta relación entre revelación y testimonio es particularmente elocuente en textos como los de 1Q27 (1QMyst) y en 4Q416 4QInstruction. En 1Q27 (=4Q300 4Qmyst fr. 3) se señala en fr.1 col I, 2 «un misterio del pecado»y «no conocen el misterio futuro, no comprenden las cosas antiguas. Y no saben qué les va a suceder; y no salvarán sus almas del misterio futuro». A los miembros de la comunidad le es revelado el «misterio futuro» en cambio a los impíos se les niega dicho conocimiento. En el dicho de Q 10,17-25 se les promete dicho conocimiento a los ignorantes. Éstos son los mártires, testigos que ven y oyen el arribo del eschaton. La terminología del martirio, esto es, el ver, escuchar, comprender, saber, y el principio de ignorancia ocupado por grupos apocalípticos durante el cambio de era, fue luego aplicada, por la comunidad Q para comprender el tiempo prometido por Dios (Schüling, 1991: 66).

De acuerdo a este principio, los discípulos y el mismo Jesús son los niños, que son colocados, no en la línea de los antiguos profetas -que no vieron no oyeron-, sino de aquellos que viven los últimos tiempos ( Tucket, 1996: 129). Lo mismo acontece con Juan, él es un profeta y más que un profeta. La designación de Juan como un profeta lo coloca en la época previa al eschaton, mientras que el añadido «más que un profeta» lo sitúa entre los discípulos, y aquéllos son testigos del arribo de la etapa escatológica (ver Lc 7,22), como lo señala Jesús a los discípulos de Juan. Se puede comprobar que detrás de tal razonamiento sapiencial está el supuesto de la profecía del judaísmo tardío y presente en los pesharím de Qumrán, esto es, que los profetas escribieron para la generación de los últimos tiempos, pero «que ellos no vieron ni escucharon»; y se cumple aquí, que Juan y los discípulos ven lo que muchos justos y profetas anhelaron ver y no lo consiguieron (ver Mt 13,17). Por tanto, es posible que Q esté afirmando la convicción que los discípulos de Cristo son bienaventurados, porque son testigos del arribo del eschaton.

\subsection{La señal de Jonás y el martirio}

La afirmación acerca de la ausencia de un sentido de la muerte en la fuente de los dichos debe atender al dicho de Q 11, 29-32//Mt 16,1-3, acerca de la señal de Jonás. En este dicho, Lucas reemplaza la expresión

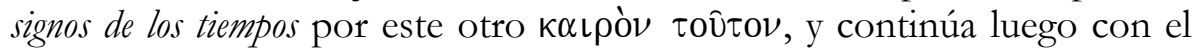
v.4 hablando de la señal de Jonás. Según esto es claro, que para la fuente de los dichos, la predicación de Jesús adquirió un carácter soteriológico para las naciones de tal modo que se constituye en una señal de los tiem- 
pos que posee carácter universal. El Hijo del hombre es una señal como lo fue Jonás para su generación en el día del juicio. El dicho de Mt 12, 40 «Como estuvo Jonás en el vientre del gran pez tres días y tres noches, así estará el Hijo del hombre en el corazón de la tierra tres días y tres noches», es redacción mateana, la versión de Lucas es más cercana a la versión de la fuente de los dichos Q 11,30 «porque así, como Jonás fue señal a los ninivitas, lo será también el Hijo del hombre a esta generación». En el dicho se cumple la paradoja que «el rechazo tendrá la consecuencia en el juicio final, cuando la obediente reina del sur y los habitantes de Nínive condenen a la malvada generación de Jesús» (Nickelsburg, 2006: 296).

La tensión metafórica que presenta la imagen de Jonás es potente. Jonás debe romper con el particularismo de la predicación judía para abrirse a la predicación de la misericordia a los paganos. Esta apertura del profeta se provoca por medio de la crisis del propio profeta. El texto de $Q$ no habla nada al respecto, pero es posible que a juzgar por los dichos de Q 13,28-30; 34-35; 14,15-24, el grupo Q experimentó el rechazo de las autoridades judías como una crisis eclesial que los llevó a abrirse a otros pueblos, posiblemente en el periodo post-pascual. En este sentido, la única señal, la señal de Jonás, puede ser entendida como una metáfora epocal en la cual se tematiza el tránsito de un profeta que se niega en primera instancia a tener misericordia de un pueblo impío, al anuncio del kerigma a los ninivitas [paganos]. La muerte y rechazo del Hijo del hombre, abre a la Iglesia a la gentilidad, por tanto, este descenso de Jonás/Hijo del hombre, se constituye en una señal de una crisis eclesial; y por tanto, esta situación es una señal del tiempo paradójica pues a causa de su muerte se anuncia el evangelio a los paganos. Podemos pensar que la señal de Jonás representa una primera reflexión soteriológica acerca de la muerte de Cristo que describe el proceso del cambio de una convicción deuteronomista del judeo-cristianismo a otra constituida por paganos.

\subsection{E1 dicho de Q 7,22-23}

En el dicho de Q 7, 22-23:

Respondiendo Jesús, les dijo: -Id y haced saber a Juan las cosas que oís y veis. ${ }^{5}$ Los ciegos ven, los cojos andan, los leprosos son limpiados, los sordos oyen, los muertos son resucitados y a los pobres es anunciado el evangelio; ${ }^{6}$ y bienaventurado es el que no halle tropiezo en mí. ... ${ }^{14} \mathrm{Y}$ si queréis recibirlo, él es aquel Elías que había de venir. ${ }^{15}$ El que tiene oídos para oír, oiga. 
Kloopenborg (2005: 163) lo clasifica como «progresión argumentativa» perteneciente a $\mathrm{Q}^{2}$. Ciertamente la expresión presente en Q Mt 3,10; Q 7,19. 20; 13,35; 19,38 remite a la figura de Elías u otras figuras proféticas de las cuales se prometía su regreso. Sin embargo como hemos ya mencionado más arriba, dicha expectativa está en relación a la espera del profeta escatológico (Cullmann, 1958: 17; Berger, 1970-1971: 397s), un Moisés o Elías redivivus que regresaría al final del los tiempos; una mesianología judía muy distinta a la visión deuteronomista para la cual estaba fuera de su horizonte histórico pensar en un regreso de un profeta al final de los tiempos. Nosotros vamos a intentar argumentar algún sentido. En el dicho encontramos las siguientes coincidencias:

- La enumeración de sujetos escatológicos según el tenor de dos textos isaianos: Is $61,1-2$ y $35,5-6$.

- La paradoja no sólo es anunciada sino que se trata de lo que han visto y oído en la praxis de Jesús (v.22).

- La identificación de Elías con la persona de Juan el bautista con una técnica pesher semejante a la practicada por grupos apocalípticos.

La enumeración de sujetos escatológicos responde a la convicción teológica acerca de la predestinación de los sujetos del eschaton que se desarrolla en movimientos apocalípticos y que comprobamos en textos como CD-A col. II, 9.13; IV,5. Estas listas pretenden mostrar los nombres o genealogías de los elegidos, como ya hemos argumentado. Por tanto no responde a una mera interpretación, sino que Jesús identifica a los elegidos de la nueva alianza, no es casualidad que el documento añada que «en aquella hora Jesús sanó a muchos de enfermedades, de plagas y de espíritus malos; y a muchos ciegos les dio la vista» $(7,21)$. Pero aún más significativo es el empleo de la terminología del martirio en el v. 22 «lo que habéis visto y oído». Los enviados se transforman ante los hechos acaecidos en testigos para Juan el Bautista que está en prisión (Mt 11, 20//Lc 3.20; Jn 3,24). El sentido de la terminología del testigo en la fuente de los dichos es primeramente escatológico y no centrado en la cuestión cristológica. En relación a la situación de cárcel tan vinculada a la terminología del testigo, la versión de Mateo es más explícita: «...cuando oyó Juan en la cárcel de los hechos de Cristo, envió a él por medio de sus discípulos» (Mt 11,2). Ahora bien, el hecho que el anuncio del evangelio está dirigido a personajes como ciegos, cojos, leprosos, sordos muestra la convicción profética que surge a regreso del destierro en cuanto que la llamada inversión escatológica se cumple al elegir Dios 
como destinatarios del eschaton a personajes paradojalmente desgraciados: pobres, ciegos, cojos, presos, etc.

\section{Otros modelos}

En contra del argumento de Steck, como ya hemos mencionado más arriba, hay textos que muestran que el envío y asesinato de profetas y justos le sigue una exaltación a los cielos. En efecto, en la fuente de los dichos, el martirio está vinculado al tema escatológico del arrebato siguiendo el modelo de 1Enoch 12,1. El dicho de Q 12, 8s que dice «el Hijo del hombres confesará a él delante de los ángeles de Dios» refleja el supuesto del Hijo del hombre ha ascendido delante del trono de Dios. También en el dicho de Q 17, 34//Mt 24,40: «uno será arrebatado ( $\pi \hat{\alpha}$ $\rho \alpha \lambda \epsilon \mu \phi \tau \eta \in \sigma \in \tau \alpha \iota)$ y el otro dejado», (Q 17,34) se mueve en el horizonte del inminente juicio del Hijo del hombre, como en 1 Enoch en el cual el arrebato se relaciona con el juicio divino inminente que sobrevendrá con el Diluvio. Esto se debe a que el motivo escatológico del arrebato se relaciona fundamentalmente con el juicio final de Dios y no con la resurrección. Éste último concepto no es aún una clave teológica dentro del esquema cristológico de la fuente de los dichos. Con otra terminología, el arrebato se vincula con el rechazo y persecución de los discípulos de Jesús y con la inminente y repentina venida del Hijo del hombre. En esta misma perspectiva se orientan los llamados a la vigilancia que aparece en el dicho de Q 12,39//Mt 24, 43: «si el dueño de casa supiese a qué hora viene el ladrón ( $\delta \quad \kappa \lambda \epsilon^{\prime} \pi \tau \mathrm{c}$ ) no dejaría que le abriese un boquete en su casa». La imagen de «la hora en que viene el ladrón» frecuente en textos escatológicos guarda relación con el verbo ' $\alpha \rho \alpha \alpha \zeta \zeta$ ' (ver Mt 12,29) que significa robar, saquear.

En el dicho de Q 17,34 los días del Hijo del hombre (vv.22.26) es una expresión paralela a la de «en los días de Noé» y «en los días de Lot» (vv.26.28) cuando sobrevino el Diluvio y «la destrucción de todos» (vv. 27.29). Tomando en cuenta que el motivo del arrebato en este logion de la fuente de los dichos está en relación al «día del Hijo del hombre» (vv.30.31); en la versión de Mt «la parusía del Hijo del hombre» (24,39); también como «la venida del Señor» (v.42), es posible concluir que estamos en presencia de un temprano estadio de la cristología la cual ha sido formulada de acuerdo a la escatología vinculada al juicio. 


\section{Los mártires olvidados}

No parece exagera afirmar que los grupos marginados, de campesinos, obreros, pescadores de nuestro Continente son «los mártires olvidados»; me parece que la teología clásica ha silenciado a menudo que el martirio es una realidad escatológica mucho más vasta que la que nos ha querido hacer pensar durante demasiado tiempo.

En nuestro escrito, hemos subrayado en diferentes partes que la entrega de la propia vida es descrita como testimonio del arribo del eschaton en los textos neotestamentarios bajo diversos enfoques teológicos, los cuales integra tanto una existencia en la precariedad como la de dar la vida como un testimonio del arribo del eschaton ante los hombres. En la fuente de los dichos existen al menos, dos paradigmas que están mezclados quizás con un tercero. El anuncio del arribo del juicio de Dios, tema central en la fuente de los dichos, se realiza teniendo como señal que cojos, sordos y los pobres, son testigos. El kerigma de la fuente de los dichos, que el reino de Dios es de los pobres, los que lloran, y son perseguidos; muestra que la fuente conoce la tradición de la pasión del justo y la tradición del destino violento del profeta. Esta última está modulada por otra variación según la cual el profeta/discípulo luego de sufrir y ser perseguido, es arrebatado o exaltado a los cielos, cuestión que está ausente de la tradición deuteronómica.

La convicción de que el reino de Dios es de los pobres y perseguidos, la revelación a los pequeños, y discípulos y su concomitante negación a los sabios y poderosos muestra que la fuente conoce la llamada inversión escatológica, núcleo de la escatología apocalíptica, según la cual el reino de Dios, las promesas de la Alianza son traspasadas al pueblo pobre y humilde. Esta tradición enmarca mediante listas a sujetos considerados secularmente como enfermos, marginados y sufrientes, los cuales son constituidos mediadores de la Alianza, en cuanto éstos son señal y testigos del arribo del reino de Dios. En este sentido las bienaventuranzas se comprenden mal si se ve en ellas un «asistencialismo divino»; se trata de algo más esencial: el protagonismo soteriológico de las víctimas. En efecto, el paradigma de la pasión del justo responde a este marco teológico, en el cual el sufrimiento, enfermedad o muerte de los justos son medio para la realización de los planes divinos. Por otra parte, en la fuente de los dichos, encontramos una fuerte impronta deuteronomista, la cual describe el martirio de acuerdo al destino violento del profeta. En este escrito, la muerte de Cristo y la de los cristianos son asumidas explicitando que es «a causa del Hijo del hombre», es decir la experiencia martirial judía no sólo está acuñada con arreglo al eschaton sino también a partir de la cristología ya presente en esta fase. 


\section{REFERENCIAS}

-Baumeister, Th. (1980). Die Anfänge der Theologie des Martyriums. Westfalen: Aschendorff Münster.

-Berger, K. (1970-1971). Zum traditiongeschichtlichen Hintergrund christologischer Hoheitstitel. New Testament Studies (17), 397-498.

-Beutler, J. (2001). Martus. En H. Balz y G. Schneider (Eds.), Diccionario exegético del Nuevo Testamento (vol. II, págs. 182-188). Salamanca: Sígueme.

-Bowersock, G. (1995). Martyrdom and Rome. Cambridge, UK: Cambridge University Press.

-Boyarin, D. (1999). Dying for God: Martyrdom and the Making of Christianity and Judaism. Stanford, CA: Stanford University Press.

-Carbullanca, C. (2011). La profecía literaria en Qumrán y en el evangelio de Marcos. El género pesher, profecía literaria judía y cristiana en el cambio de era. Germany: EAE. LAP Lambert academic Publishing GmbH \& Co.

-Collins, J. (1984). Daniel with an Introduction to Apocalyptic literature (V. XX). Michigan: William Eerdmans Publishing Company.

-Cullmann, O. (1958). Die Christologie des Neue Testaments. Tübingen: J.C.B. Mohr.

-Droge, A. \& Tabor, J. (1992). A Noble Death. Suicide \& Martyrdom among Christians and Jews Antiquity. New York: Harpers San Francisco.

-Dupont, J. (1979). Le Beatitudini. Il Problema Letterario. La buona Novella. Roma: Edizione Paoline.

-García Martínez, F. (2003). Wisdom at Qumrán: Wordly or Heavenly? En F. García Martínez (Coord.), Wisdom and Apocalypticism in the Dead Sea Scrolls and the Biblical Tradition (págs. 1-15). Leuven-Paris: Leuven University Press.

-Gnilka, J. (1998). Teología del Nuevo Testamento. Madrid: Trotta.

-Hahn, F. (1995). Christologische Hoheitstitel. Göttingen: Vandenhoeck \& Rucprecht.

-Hoffmann, P. (1972). Studien zurTheologie der Logienquelle. Münster Wesfalen: Verlag Aschendorf.

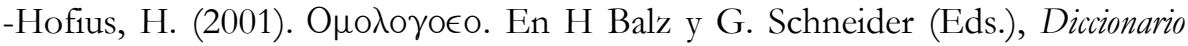
exegético del Nuevo Testamento (vol. II, págs. 542-551). Salamanca: Sígueme.

-Janowski, B. (2003). Sühne als Heilsgeschehen. Studien zur Sühnetheologie der Priesterschrift und zur Wurzel KPR im Alten Orient und im Alten Testament (WMANT 55). Vluyn: Neukirchen-Vluyn.

-Jeremías, J. (1971). NewTestament Theology. London: SCM Press.

-Kloppenborg, J. (2005). Q. El evangelio desconocido. Salamanca: Sígueme.

-Lohse, E. (1963). Märtyrer und Gottesknecht. Untersuchungen zu urchristkuchen Verkundigun vim Suhntod Jesu Christ. Gottingen: Vandenchoeck \& Rupercht

-Manson, T. W. (1937). The sayings of Jesus. London: SCM Press Ltda.

-Meadors, E. (1997). Jesus, the Messianic Herald of Salvation. Massachusetts: Hendrickson Publischer.

-Nickelsburg, G. (2006). Resurrection, Inmortality, and Eternal Life in Intertestamental Judaism and Early Christianity. New Haven: Harvard University Press. 
-Nómez, N. (2013). Escrito sobre Robka. Antología poética de Pablo de Robka. Talca: Editorial Universidad de Talca.

-Rahner, K. (1983). Dimensiones del martirio. Concilium (183), 321-324.

-Russell, D. (1964). The Method and Message of Jewish Apocalyptic. London: T\&T.

-Schillebeeckx, E. (1981). Jesús la historia de un viviente. Madrid: Cristiandad.

-Schüling, J. (1991). Studien zum Verbälnis von Logionquelle und Markusevangelium. Würzburg: Echter Verlag.

-Steck, O. (1967). Israel und das Gewaltsame Geschick der propheten (Vol. 23; Wiseenschaftliche Monographien zum Alten und Neuen Testamente). NeukirchenVluyn: Neukirchener Verlag.

-Strecker, G. (2000). Theology of New Testament. Walter de Gruyter, Lousville: Westminster John Knox Press.

-Strecker, G. (2001). Maкapıoб. En H. Balz y Schneider, G. (Eds.), Diccionario exegético del Nuevo Testamento (vol. II, págs. 126-135). Salamanca: Sígueme.

-Theissen, G. (1992). Social reality and the Erly Christians. Theology, Ethics and the World of the New Testament. Minneapolis: Fortress Press.

-Tucket, Ch. (1996). Q and the history of Early Christianity. Edinburgh: T\& T Clark.

Sumario: 1. El martirio en Latinoamérica; 1.1. ¿Qué se entiende por martirio?; 1.2. Hipótesis; 2. Contexto de Q; 3. El envío del profeta y su destino violento; 3.1. La historia de Israel como rechazo de los enviados; 3.2. Juan el Bautista y el juicio; 4. Paradoja y visión deuteronomista; 4.1. Doctrina de retribución y las bienaventuranzas; 4.2. Las bienaventuranzas; 4.3. Inversión escatológica; 4.4. La inversión escatológica y carácter soteriológico de las víctimas; 5 . Lista de sujetos escatológicos; 5.1. Inversión escatológica y lista de personajes; 5.2. El tema de la sabiduría; 5.3. La revelación de Q 10,21; 5.4. La señal de Jonás y el martirio; 5.5. El dicho de Q 7,22-23; 6. Otros modelos; 7. Los mártires olvidados; Referencias. 